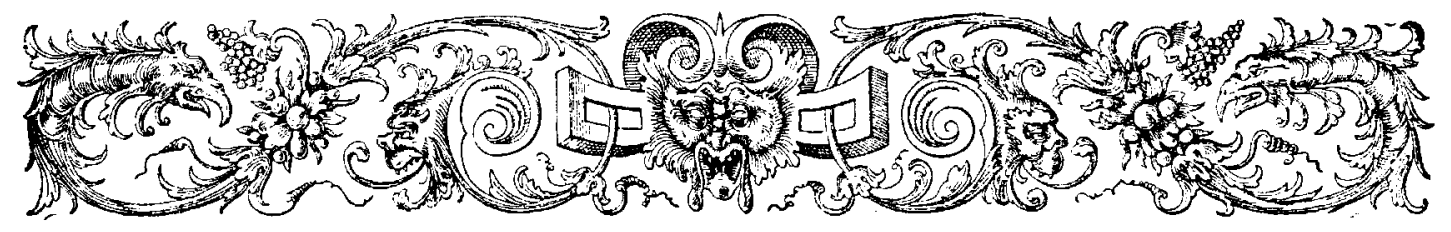

\title{
Een merkwaardige verzameling Teekeningen
}

DOOR

E. W. MOES.

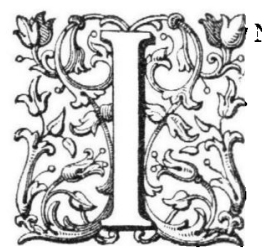

N het Prentenkabinet van 's Rijks Museum te Amsterdam berust een album, waarin 56 teekeningen in zwart krijt geplakt zijn. Ze zijn kennelijk van één hand en bevatten vluchtige schetsen naar schilderijen. Achter op een der teekeningen $\left(n^{\circ} .5\right)$ is cen fragment van een lijstje, waarschijnlijk aangevende, waar de verschillende afgebeelde schilderijen gevonden werden.

$$
\text { Waer elck huis to vin[den] }
$$

Ten huise van de heer SIMON GRASTw[INCKEL].

Ten huise van de heer ......... VAN BE......

Ten huise wan de heer ANTONIE VAN BRON[CHORST?]

Ten luise van den capitein VAN DER B......

Ten huise van Monsr. WILleM DE LANGE.

Ten huise van Mons'. NICOLAAS VAN DER WERCK(?)

Ten huise van Monsr. JoHAN PERSIJN.

Ten huise wan Mons ${ }^{r}$. AdRAHAM DE.....

Ten huisi van Mons. ADAM PICK.

Ten huise van REINIER VERMEER ${ }^{1}$ ).

Ten huise van LEONAERT BRAMER.

1 Dit is de vader van Johannes Vermeer. 
Heel duidelijk is dit geschonden lijstje niet, maar het verschaft toch licht genoeg om te doen weten, in welke stad de afgebeelde kunstwerken moeten gezocht worden, want wij treffen er eenige bekenden onder aan. Zoowel ADAM Pick als Leonaer T BRAMER waren schilders te Delft. De laatste woonde daar tot zijn dood in 1674 , de eerste woonde er tot 1655 , toen hij zich in het Leidsche St. Lucasgilde op liet nemen. Wij zullen dus niet ver mistasten, wanneer wij het ontstaan van deze teekeningen op ongeveer het midden der r 7 de eeuw vaststellen.

De verzameling is oorspronkelijk grooter geweest, gelijk blijkt uit de nummers, die de meeste teekeningen dragen. Het laagste nummer is 4 , het hoogste 107 , en thans bevat het album slechts 56 teekeningen.

Op twee uitzonderingen na heeft dezelfde hand, die de teckeningen gemaakt heeft, er ook op geschreven, wie de schilder van de stukken was. Deze namen zijn ongeveer in denzelfden tijd door hem zelf of door een ander met inkt opgedikt. En die namen zijn het, die aan de verzameling een bijzondere waarde ver- leenen, want zij doen het werk kennen van menig ter nauwernood bekend of geheel onbekend meester.

Ik laat ze volgen in de volgorde, waarin ze opgeplakt zijn.

I [53] P. Bamboots, Na de jacht.

Een jager geeft een troep honden wat van den buit. Rechts komen een paar honden aansnellen, in bedwang gehouden door een jager. Links nog een jager te paard, terwijl een vierde zijn laars los maakt. Op den achtergrond in het midden een zware boom, en links een hut. Rechts uitzicht op een bergachtig landschap (h. 28 br. 40).

2 [45] Bamboots. Herder met vee.

Voor een hut staat en ligt eenig vee, bewaakt door een herder. De achtergrond is heuvelachtig (h. 39. br. 30).

PIETER VAN LAER's werk is op merkwaardige wijze uit ons land verdwenen, en dat nog wel, terwijl het hier in de I7de en I8de eeuw zeer gezocht was. HoubrakeN vertelt zelfs, dat zijne schilderijen uit Italië hier ingevoerd werden ${ }^{1}$ ).

3 [92] A. vī BeIEREN. Stilleven 2).

Op een tafel, waarover een servet los geworpen ligt, staat een waterkan met half geopend deksel, een fluit, een schaal met fruit, een schotel

1) ARNold Houbraken, De groote schouburgh enz. Amsterdam i7 I8, I p. $362,3^{6} 3$,

2) Boven hebben wij gezien, dat de teekenaar ook in het huis van ADAM PICK het een en ander gevonden had. Onder zijn in I653 geinventariseerden inboedel (Oud-Holland VI p. 297) komt ook voor ${ }_{2}$ Een freuyt aan VAN BEYran". Mogelijk is dit he: hier afgebeelde stuk. 
met kreeft, een kleine schotel met een half geschilde citroen en nog eenige voorwerpen (h. $28^{1} / 2$ br. $39^{1 / 2}$ ).

4 [7I] M. DE BERCH. Slapende nimf bespied door een sater.

Een naakte nimf ligt aan den rand van een bosch te slapen, terwijl naast haar een gevulde pijlkoker ligt. Tusschen een boomgroep rechts komt het hoofd van een sater te voorschijn (h. $29 \frac{1}{2}$ br. 40).

MATThys VAN DEN BERGH, in I649 Hoofdman van het St. Lucasgild te Delft, en in 1687 aldaar gestorven, is voornamelijk bekend door zijn teekeningen naar andere meesters. In de zeldzaam voorkomende schilderijen van zijn hand imiteerde hij ook bij voorkeur, en hij kwam daar ook rond voor uit. Op een stuk, behoorende tot het Kon. Pruissisch Domein, en voorstellende een grot met saters, nimfen en een oude vrouw, teekende hij onverholen $\overline{\mathrm{MV}}$ BERGHE IMITANDO. F. I6.... De compositie is samengesteld uit verschillende brokstukken van werken van RUBBENS. Ook deze teekening herinnert sterk aan RUBBENS.

5 [IO7] Henricus Bramer. Ruiterijgevecht.

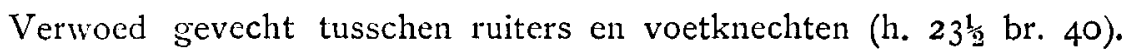

Henricus Bramer is van elders niet bekend. De veronderstelling ligt voor de hand, dat er een verwarring heeft plaats gehad met den bekenden LEONARD BRAMER, maar het behandelde onderwerp is voor dezen historieschilder zeer vreemd, en onze kennis van de familie BRAMER is nog zóó gebrekkig, dat er zeer goed een schilder HENRICUS BRAMER kan geweest zijn, zonder dat wij hem nog kennen. J. Matham graveerde in 1598 een St. Apollonius en St. Martha naar PAUL BRAMER, en ook dat familielid is nog volkomen onbekend. In de collectie CzERnin te Weenen wordt een schilderij met geharnaste ruiters te paard toegeschreven aan LEONARD BRAMER. Wellicht is dit ook van den hier voor het eerst genoemden HENRICUS,

6 [IO5] L. Bramer. De Besnijdenis.

De priester zit achter een tafel en heeft het Christuskind op den arm. Naast hem houdt een jongen een brandende kaars. Vóór de tafel staat rechts een man wierook te zwaaien en links zit een ander in een boek te schrijven, beiden in priestergewaad. Links achter de tafel nog eenige toeschouwers (h. $30 \frac{1}{2}$ br. $28 \frac{1}{2}$ ).

LEONARD BRAMER heeft dikwijls de Besnijdenis geschilderd. Een zeer gehavend exemplaar is in het Museum te Brunswijk, als pendant van Jezus en de schriftgeleerden, gemerkt: L. BRAMER I $64 \ldots$ (h. 62 br. 49); beide stukken 
waren in 1738 verworven. Ook is er een in het Museum te Karlsruhe (h. 24 br. 24), en was er in I 786 een in de coll. MeIL te Berlijn. Voorts wordt in het Museum te Gotha een Besnijdenis aan BRAMER toegeschreven, evenals een andere in de coll. LANFRANCONI te Pressburg, welk werk vroeger tot de verzamelingen ZAMPIERI te Bologna en KAUNITZ te Weenen behoord heeft en daar voor een REMBRANDT werd aangezien. Of een van deze schilderijen het in het album afgebeelde is, zal een vergelijking kunnen uitmaken. In den inventaris van den inboedel van Odevaert Sonnevelt, te Delft in 1648 opgemaakt, werd "Een besnijdenis Christi" van hem op $f$ 25.- getaxeerd.

7 [46] L. Bramer. De kindermoord te Bethlehem.

Kleine figuren. Links vluchten eenige vrouwen, door een soldaat achtervolgd. Rechts is het moorden in vollen gang (h. 40 br. 30 ).

8 [60] C. Couwenberch. Rechtspraak van ........ $\left.{ }^{1}\right)$.

Een koningin, met den scepter in de rechterhand, zit op haar troon. Rechts voor haar staat een gerechtsdienaar op het punt, een voor haar geknield en geboeid man te onthoofden (h. $30 \frac{1}{2}$ br. 40 ).

9 [-] C. Couwenberch. Mythologische voorstelling.

Aan het strand staan eenige naakte en half naakte vrouwen, te paard en te voet, terwijl een vrouw(?) uit de golven te voorschijn komt (h. $28 \frac{1}{2}$ br. 32 ).

IO [70] C. Couwenberch. Jesabel door honden verscheurd.

Drie honden vallen aan op de koningin, die half naakt van de trappen geworpen is. Haar kroon ligt voor haar op den grond (h. $28 \frac{1}{2}$ br. 40 ).

Geen enkele schilderij van dezen in zijn tijd zoo beroemden schilder is bekend, al wordit er in het Museum te Keulen een groot aantal portretten als van zijn hand getoond; immers de toeschrijving van al deze werken steunt op niets. De voorstellingen van twee der bovengenoemde tafreelen heb ik niet kunnen verklaren. Het ging mij hierbij, zooals het in 1725 den taxateur van den inboedel van Mr. WILLEM VAN DER GRAEFF is gegaan, die eenvoudig noteerde: Een tragedische historie door COUWENBERGH ${ }^{2}$ ).

1) Ofschoon het mij niet duidelijk is, waarop deze voorstelling doelt, meen ik er toch een pendant van no. 10 in te zien.

2) Oud-Holland VIII p. 224.

Ond-Holland, 1895 . 
I I [-] Crabetje [Jan Asselyn]. Landschap met stoffage.

Drie muilezels met twee drijvers. Links een groote ruine. Rechts

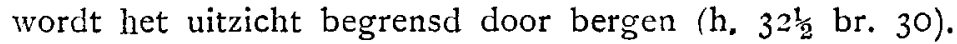

i2 [30] Crabbetge [JaN Asselijn]. Landschap met stoffage.

Een kudde schapen en bokken, met een herder. Links begroeide heuvels (h. $28 \frac{1}{2}$ br. 40).

I 3 [55] ADAM Elshemer. Vlucht uit het brandende Troje.

Op den voorgrond Aeneas met zijn vader Anchises op den rug (h. 30 br. 40 ).

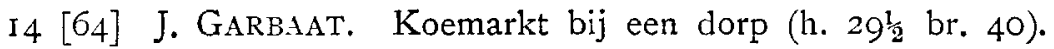

Wie deze schilder is, heb ik niet kunnen vinden.

I 5 [-] P. Groenewegen. Stilleven.

Naast een groote tobbe liggen twee meloenen en eenige appelen, en staat een schaal met druiven (h. $31 \frac{1}{2}$ br. 29).

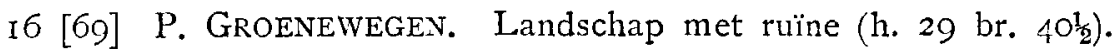

Van Pieter Groenewegen, in 1626 in het gilde te Delft ingeschreven, doch in 1658 in zijn geboorteplaats 's Gravenhage overleden, is mij maar eens een schilderijtje onder de oogen gekomen, en wel een landschapje in de verzameling van Mevr. de Wed. VIEwEG te Brunswijk. Het is gemerkt: P. GRoENE-WEGEN, en herinnert aan de landschappen van PIETER MOLyN. In Delftsche inventarissen komt zijn werk veel voor.

I 7 [57] G. Honthorst. Herder en herderin.

Een herder bespeelt de fluit en zit naast een herderin, die haar linkerhand om zijn schouder geslagen houdt (h. 27 br. 28).

I 8 [68] G. Houck GeEst. Zuilengang van een paleis.

In het midden ontspringt een fontein (h. 29/ br. 39).

De Hagenaar GERrit Houckgeest heeft geruimen tijd te Delft gewoond, waar hij gelegenheid vond, herhaalde malen het grafteeken voor WILLEM I in de Nieuwe Kerk te schilderen. Bijna altijd zijn kerkinterieurs, en dan vooral van Delftsche kerken, zijn onderwerpen. Schilderijen als het in het album afgebeelde vindt men van hem in de National Gallery te Edinburgh, in het Museum te Aken en in het Hertogelijk slot te Dessau.

I9 [-] GaERdYN [KAREL DU JARDIN]. Landschap met stoffage.

Een beladen muilezel wordt door den drijver bij den toom geleid, 
gevolgd door een muilezel die door een vrouw bereden wordt. Heuvelachtig landschap (h. 34 br. 29).

20 [93] L. DE JONG. De verloren zoon.

Rechts zit aan tafel de verloren zoon met een vrouw op de knieën, terwijl een andere vrouw hem wijn inschenkt. Een derde speelt op de luit en nog anderen zitten aan de tafel. Rechts op den achtergrond een groot ledikant, links treedt iemand door de half geopende deur binnen (h. 29⿺ br. 38).

2 I [9o] L. DE JONG. Jacht.

Een aantal honden vallen een hert aan, terwijl rechts een jager aan

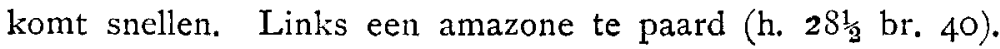

22 [-] J. Junius, Ruitergevecht.

Gevecht tusschen ruiters en voetknechten (h. 27 br. 40).

Ook IsAaK Junius heeft te Delft gewoond. In het Museum te Pesth is het eenige schilderij, dat mij van zijn hand bekend is. Het is van I643 en stelt ook een ruitergevecht voor.

23 [52] P. Lastman. Bathseba in het bad.

Bathseba zit geheel naakt in het bad. Een vrouw wascht hare voeten, een ander kapt haar haar. Naast de sierlijke fontein, die gevormd wordt door een dolfijn, bereden door een engeltje, staat een

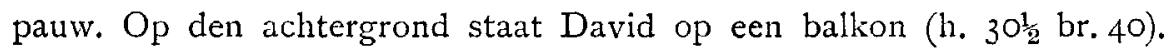

Een dergelijk onderwerp door PIETER LASTMAN was in I666 in de coll.

HENDRICK BUGGE VAN RING te Leiden.

24 [-] P. Lastman. Mythologische voorstelling.

Minerva, kenbaar aan helm, speer en borstharnas en aan de uil die naast haar staat, zit in een grot. Een man komt een groot koelvat aantorsen (h. $35 \frac{1}{2}$ br. 29).

25 [59] J. LIEVENSE. Jacob valt flauw, als zijn zoons hem Jozefs rok brengen (h. $30 \frac{1}{2}$ br. 40 ).

26 [29] J. LIEvense. Bergachtig landschap.

De hooge brug, waaronder een waterval zich uitstort, is een motiet uit Tivoli (h. 28 br. 40 ).

Een der zeer zeldzaam voorkomende landschappen van JAN LIEvENSz. is in het Museum te Berlijn. Ook Petrus Scriverius had er een in zijn kabinet ${ }^{1}$ ).

1) Oud-Holland XII p. 62 . 
27 [74] J. Lis. Badende nimfen (h. 29 br. 38).

Het is wel opmerkelijk dat hier in het midden der I 7 de eeuw JAN LIS al verward wordt met DIRCK VAN DER LISSE.

28 [79] [PETER vaN] Mol. Het lijk van Christus wordt weggedragen (h. 38 br. 27).

29 [76] Molenaer. Jager en melkmeid.

Een jager en een melkmeid zitten onder een boom te vrijen. Voor hen staan drie honden eil twee melkemmers naast een juk en twee doode hazen (h. 28 br. 38 ).

Een dergelijk onderwerp door JaN Miense Molenaer in de coll. Liechtenstein te Weenen heeft een ander formaat. Op den inventaris van den inboedel van Thomas RobyN, Delft I684, komt van hem een schilderij voor, dat genoemd wordt "Een kinnetastertje". Deze benaming komt wonderwel overeen met de teekening in het album.

30 [66] Monincks. Mythologische voorstelling.

Mercurius komt aanvliegen naar een paar nimfen, die in elkanders armen liggen. Cupido staat er naast en mikt op een der nimfen; een persoon neemt verschrikt de vlucht (h. 34 br. 29).

3 I [65] MonINCKS. Galatea.

Galatea rijdt op een schelp over de zee, getrokken door dolfijnen. Op een tweede schelp volgt Triton en andere zeegoden. In de lucht eenige minnegoodjes (h. $30 \frac{1}{2}$ br. 40 ).

32 [58] Monincks. Het kind Jupiter door de geit Amalthea gevoed.

Een sater zit er naast op een fluit te spelen (h. $30 \frac{1}{2}$ br. $39 \frac{1}{3}$ ).

Denkelijk wordt Pieter Monincks bedoeld.

33 [72] A. Palemedes. Soldatenwachtkamer.

In het midden staat een officier bevelen uit te deelen. Rechts zitten eenige soldaten onder de schouw, en ligt een groote trommel (h. $28 \frac{1}{2} \mathrm{br}, 40 \frac{1}{2}$ ).

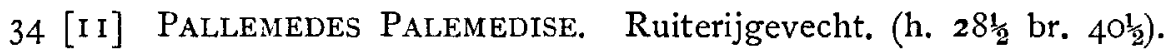

35 [9] Antoni Palemedes. Soldatenwachtkamer.

Pendant van $n^{\circ}$. 33. De officier staat voor de schouw, eenige gevangenen liggen geknield vóór hem.

36 [62] P. PAlEMEdesen. Ruiterkamp (h. $27^{\frac{1}{2}}$ br. 40\%).

Legerkamp met tenten. Op den voorgrond rechts een krijgsman te paard, die een op den grond zittenden gevangene met zijn sabel dreigt.

37 [85] A. PICK. Stilleven met mansportret.

Op een tafel staat een bokaal, een kan, een komfoor en ligt o. a. 
een viool. Achter de tafel zit een man met een grooten hoed op een pijp te rooken (h. 37 br. 29).

Van ADAM PICK, wiens zonderlinge levensloop elders in dit tijdschrift ${ }^{1}$ ) uitvoerig is medegedeeld, kan $\mathrm{ik}$ geen schilderij aanwijzen. In den inventaris van den inboedel van de weduwe van Johan GerRITsz. BercK, overleden te Delft in 1647 , was van hem een landschap.

38 [5..] E. VĀ POEL. Vreugdevuren te Delft.

Langs de Oude Delft staan brandende pektonnen. Links de toren van de Nieuwe Kerk (h. 40 br. 28).

Ik vermoed dat deze vreugdevuren ontstoken zijn ter viering van het sluiten van den Vrede van Munster. Een dergelijk stuk van EGBERT vaN DER POEL is in het Museum te Keulen.

39 [98] EgBert va Poel. Koestal.

Een boer is bezig den stal op te vegen, terwijl rechts een ander binnentreedt (h. 29 br. 32).

40 [40] C. Poelenburch. Aanbidding der Koningen.

In een ruïne zit links op een verhevenheid Maria met het kind Jezus op haar schoot. Een der koningen ligt geknield, de beide anderen staan er achter met een talrijk gevolg, dat geschenken draagt. In de lucht zweven een paar engeltjes (h. 40 br. 39).

Een Aanbidding der Koningen, door Cornelis van Poelenburch, is in het Museum te Dresden. Een andere was in 1786 in het Neue Schloss te Sanssouci. Het stuk met dezelfde voorstelling, dat in het Museum te Kassel aan POELENBURCH wordt toegeschreven, dunkt mij eerder van de hand van BARTHOLOMEUS BREENBERG.

4I [44] C. Poelenburch. Landschap met figuren,

Een herder met eenig vee staat te praten met een man, die een paard bij den toom houdt. Rechts op den achtergrond een huis (h. 37 br. 38 ).

42 [54] C. Poelendurch. Landschap met ruïnes en eenige figuren (h. 28 br, 40\%).

43 [4] A. Pinaker. Herders met vee.

Een herder op een muilezel staat te praten met een vrouw (h. 27 br. 33).

44 [-] A. Pinaker. Landschap met vee.

Een staande en een liggende koe worden door een herderin bewaakt (h. 27 br. 33 ).

1) Oud-Holland, VI p. 269 vlg. 
45 [-] A. Pijnaker. Landschap met figuren.

Twee paarden staan te drinken, terwijl de ruiters afgestapt zijn (h. 34 br. 29).

$46[75]$ ?. De schapenscheerster.

Rechts zit een vrouw een schaap te scheren. Links een troep schapen (h. 28 br. 40 ).

"Dit onbekend" heeft de teekenaar er onder geschreven, maar de hand, die elders die onderschriften alle gedwee overdilite, meende hier beter te weten, en schreef er REMBRANT onder. Maar stellig had hij het mis.

47 [65] C. Saftleves. Koemarkt.

Rechts op den voorgrond wordt een koe gemolken (h. 30 br. $4 \mathrm{I}$ ).

Veemarkten van de hand van CorNelis SAFTLEven zijn o. a, in het Museum te Valenciennes (I640), in de Hermitage te St. Petersburg en in de coll. Liechtenstein te Weenen.

48 [19] Harceles Segers. Landschap met bergen rechts (h. 30 br. 4r).

Dit landschap van Hercules Seghers is hiernevens afgebeeld '), daar het waarschijnlijk ergens als cen REMBRANDT zal hangen. Een landschap in het Museum te Berlijn, nu ter echt aan Hercules Seghers teruggegeven, hing voorheen in de collectie SuErmondt te Aken ook als een REmbrandt. Evenzoo in de Uffizi te Florence, waar een landschap van SEGHERS onder den naam van REMBRANDT hangt en als zoodanig door BRAUN gephotographeerd is.

49 [33] J. VĀ VELDE. Bestorming van een dorp door ruiters.

Eenige ruiters bestormen een dorp, maar worden door boeren teruggedreven (h. 29 br. 40).

Dit stuk is vermoedelijk geschilderd door den JAN VAN DE VELDE, die zich meer bekend heeft gemaakt door zijne gravures. Het landschap met de historie van Tobias, dat hem in het Musemm te Brunswijk wordt toegeschreven, is vermoedelijk niet van zijn hand. Daarentegen is een serie van de twaalf maanden in de Academie te Venetië, die daar als werken van JACQuEs Callot tentoongesteld zijn, denkelijk aan JAN VAN DE VELDE toe te schrijven ). In den inventaris van den inboedel van HENDRICK BUGGE vAN RiNG, Leiden I666, komen voor "Vier stuckgens met ruijters en paerden rijdende met Sijn Hoocheijt Prins FREDERIK naer Scheveningen van Mr. JAN VAN DE VELDE".

50 [94] Vosmaer. Stille zee.

Links een fregat, voorts verspreid eenige kieine scheepjes (h. $29^{\frac{1}{2}}$ br. $38 \frac{1}{2}$ ).

Dit is Nicolaes Vosmaes, broeder van den meer bekenden Daniel

1) Naar een doortrek, vervaardigd door den heer J. A. Boland.

2) Nederlandsche Spectator 1870 p. 63 . 


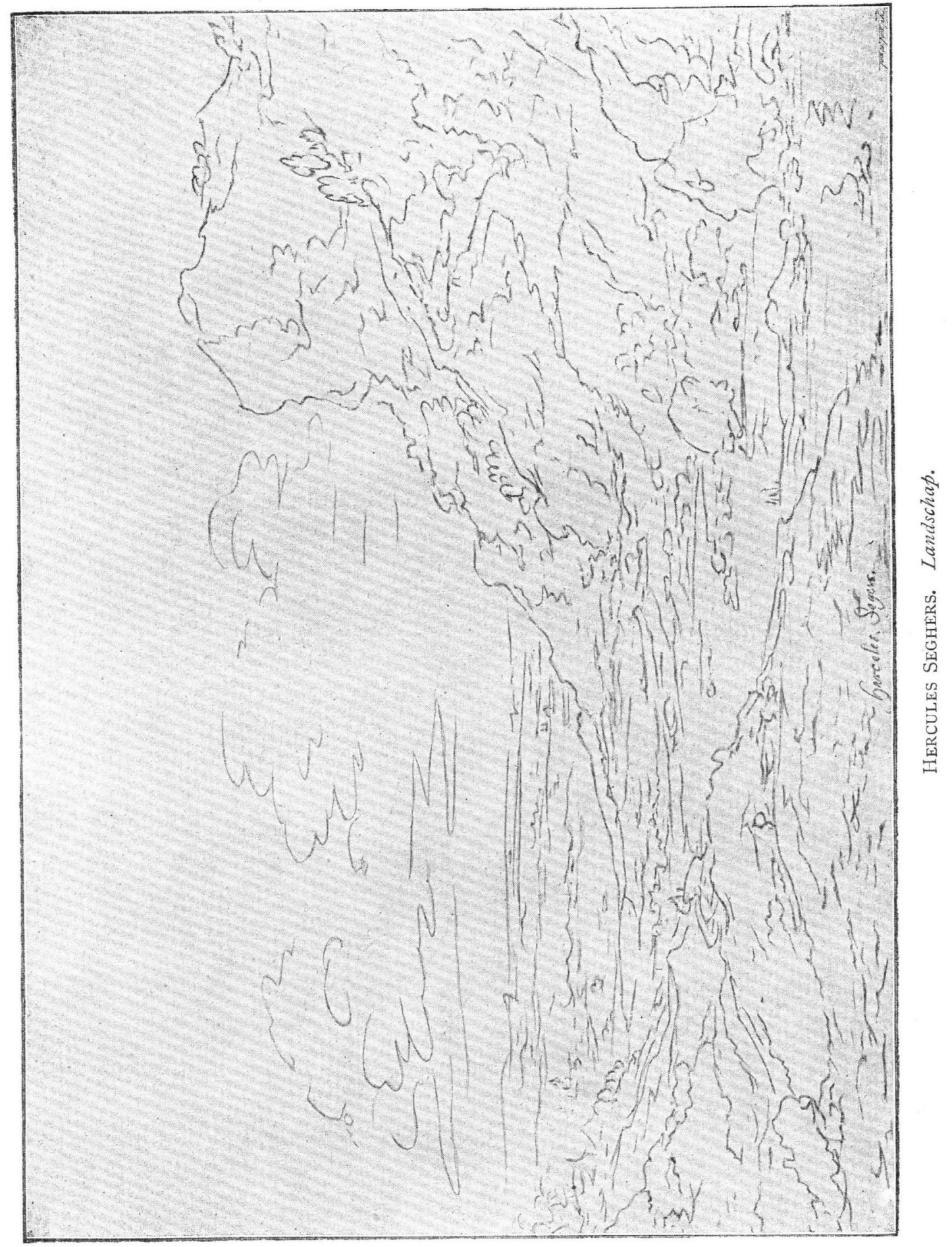


VOSMAER. Een strandgezicht vall hem kwam voor op de veiling coll. Höch te München, 1892.

5I [9] VROOM. Riviergezicht.

In een rivier met begroeide oevers wordt een schuit voortgeboomd (h. 24 br. 40).

Dit is CORNELIS VROom, zoon van den bekenden zeeschilder HENDRICK VROOM. Zijne landschappen o. a. in de musea te Berlijn en te Schwerin beginnen steeds meer de welverdiende andacht te trekken.

52 [18] Weninkx. Bergachtig landschap.

Eenige ruiters leiden hunne paarden door het water. De oever is heuvelachtig. In de verte een stadje (h. 28 br. 40).

Natuurlijk JAN BAptist WeENix.

53 [21] A. Willers. Storm op zee.

Eenige schepen worden tegen de rotsen op de kust geslingerd (h. 28 br. 40).

Adam niet Abraham Willaerts.

54 [25] Tomas Wyck. Schuur met eenige figuren (h. 45 br. 39).

55 [-]? Italiaansch landschap (h. 29 br. $38 \frac{1}{2}$ ).

$56[80]$ ? Fragment van cen Laatste Oordeel.

\section{B L A D V L L I N G.}

"Pace tamen Tua, mi Lector, hic addam Epigramma Ingeniosissimi Pö̈tae

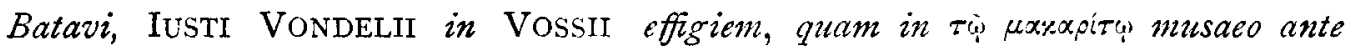
octennium delineavit SANURARDUS; quod nos è Belgico ita aliquando vertimus:

Sex denos nihil est mumiret si Vossius annos, Candidior niveis frons crit illa comis;

Hâc habitat cuncti sub fronte scientia secli, Condita quaeque libris conditu habet cerebro.

Quid chartis hominem cingis, SANDRARDE, librisque,

Charta, liber, quicquam si capit, ille capit".

Deze vertaling van het beroemde vers van VONDEL „Laet sestigh winters vry het VOSSENhooft besneeuwen" is het werk van FraNCISCUS JunIUS, den zoon van Vossius' zwager JOHAN CASIMIR JUnius, en is door hem geplaatst in het "Lectori benevolo" van de door hem bezorgde uitgave van Vossius' "De IV artibus popularibus, Amst. 1650. $4^{\circ}$.

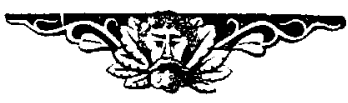

